\title{
Broad themes of difference between French and Americans in attitudes to food and other life domains: personal versus communal values, quantity versus quality, and comforts versus joys
}

\author{
Paul Rozin ${ }^{1 *}$, Abigail K. Remick ${ }^{2}$ and Claude Fischler ${ }^{3}$ \\ ' Department of Psychology, University of Pennsylvania, Philadelphia, PA, USA \\ 2 Department of Psychology, University of Toronto, Toronto, ON, Canada \\ ${ }^{3}$ Centre Edgar Morin, UMR 8177 EHESS-CNRS, Paris, France
}

\section{Edited by:}

Asifa Majid, Max Planck Institute for

Psycholinguistics, Netherlands

Reviewed by:

Disa Sauter, Max Planck Institute for

Psycholinguistics, Netherlands

Richard A. Shweder, University of

Chicago, USA

Alan P. Fiske, University of California

Los Angeles, USA

*Correspondence:

Paul Rozin, Department of Psychology,

University of Pennsylvania, 3720

Walnut Street, Philadelphia, PA

19104-6241, USA.

e-mail: rozin@psych.upenn.edu
Analysis of previous literature on the role of food in life in France and the United States suggests some fundamental differences in attitudes which may generalize outside of the food domain. Questionnaire results from French and American adults suggest that, compared to the French, Americans emphasize quantity rather than quality in making choices, Americans have a higher preference for variety, and Americans usually prefer comforts (things that make life easier) over joys (unique things that make life interesting). The American preference for quantity over quality is discussed in terms of the American focus on abundance as opposed to the French preference for moderation. The American preference for variety is reflective of Americans' more personal as opposed to communal food and other values.

Keywords: food, pleasure, variety, culture, France, USA
In recent decades, there has been increased interest in how cultural forces shape the human mind and human life, culminating in the development of a new subdiscipline in psychology, cultural psychology (Shweder, 1995; Kitayama and Cohen, 2007). Understandably, the focus has been on strikingly different cultures, primarily differences between East Asian or South Asian cultures and EuroAmericans (Markus and Kitayama, 1991; Fiske et al., 1998; Nisbett, 2003). In this study we contribute to the understanding of the link between culture and psychology, but depart from most prior work in two ways. First, we compare samples from two "cultures," France and the United States, which are very much alike on many of the dimensions that have been the focus of cultural differences in the cultural psychology literature. Second, we focus on particular domains of life. Some of our items, and much of the stimulus for examining more general French-American differences, come from the work of ourselves and others on differences in French and American approaches to food.

It is our sense that there are substantial differences between French and Americans in the food and pleasure domains, and because the societies are relatively similar in many other respects, it may be possible to draw some finer distinctions in areas of difference. The comparisons and dimensions of difference that we propose to isolate may be of particular relevance in the domain of health, since both obesity (Laurier et al., 1992) and heart disease (Renaud and de Lorgeril, 1992) are notably lower in France than in the United States. There is a lower heart disease rate in France even though the French eat a higher percentage of calories as both fat and animal fat (Renaud and de Lorgeril, 1992). Both cultures are concerned with weight control and place great emphasis on being thin (Stearns, 2002). And as Payer (1988) writes, "The French concern with thinness may seem paradoxical in light of the French preoccupation with food. But it is not the quantity of food that distinguishes France from the rest of the world: it is the care taken with the quality and character of what is eaten" (pp. 55-56). The French have a low rate of obesity in the developed world, but they spend more time eating daily than any other country (OECD, 2009), and they spend more time during the day with food as a focus than do Americans (Kahneman et al., 2010). These findings indicate that there are certain cultural values and practices that allow the French to separate food and the pleasure of eating from the drive to be slim.

Our prior research, our acquaintance with the two cultures, and important historical writing on these two cultures (notably Mennell, 1996; Stearns, 2002; Levenstein, 2003a,b) have led us to hypothesize some areas where there may be interesting psychological cultural differences. Some of these differences may transcend the domain of food and eating. One, that our prior research has indicated, but that the present study does not directly address, is the separation of the pleasure of eating from concerns about health and guilt about potential weight gains which is more characteristic of the French (Rozin et al., 1999). We expect that this enjoyment factor may be more general in France, and may be due, in part, to the historical role of Catholicism in France and Protestantism in the United States.

In this paper, we address three other themes that have emerged, in part, from our prior research. One is the idea that French have more communal food values than Americans, and that this may 
extend to other domains. We measure one aspect of this in the present study: the desire for variety across domains. A second theme is the focus on quality as opposed to quantity in the French. A third is a greater preference for joys (unique events) as opposed to comforts (activities or expenditure that make life easier) among the French. A fourth theme, also suggested by our prior work, and illustrated by smaller portion sizes among the French (Rozin et al., 2003), is a favoring of moderation as a guiding principle among the French, as opposed to abundance among Americans. This is illustrated by the popularity of all-you-can-eat restaurants in the United States, and the idea that one should stuff oneself on the national holiday, Thanksgiving. We do not directly address the moderation-abundance theme in this study, but our measure of quality versus quantity is closely related to it.

\section{PERSONAL VERSUS COMMUNAL VALUES}

It is widely accepted that the pursuit of individual as opposed to collective values is a feature of Western, capitalist, and developed/wealthy countries (Markus and Kitayama, 1991; Kitayama and Cohen, 2007). This set of features essentially defines Western Europe, North America, and Australia/New Zealand. In any dichotomy derived from this type of consideration, France and the USA would always find each other in the same individualized category. Our distinction between personal and communal values is distinct from individualism-collectivism, but bears some relationship to it because shared values is a common feature of collectivism and communal values. Communal values in food can be conceived in two different ways. One is the path from communal to social: shared food, and eating and meals as occasions for social interaction. Food and eating seem to be a much more social event in France, empirically illustrated by the facts that: (a) meals take longer in France (Rozin et al., 2003; Krueger et al., 2009) and duration of the meal is positively related to the number of people eating in the group (de Castro and Brewer, 1992; Sommer and Steele, 1997; Bell and Pliner, 2003) and (b) that sociality is referred to more explicitly as part of the memory and experience of meals (Krueger et al., 2009; Remick et al., in preparation). It is an empirical question as to whether increased social involvement with respect to food generalizes to other French activities.

A second manifestation of communal values, the type that we will investigate in this study, has to do with shared values about what is good food. France has a longer history and a much better defined cuisine and sense of the role of food in life than does America. One consequence, we maintain, is that French seek less micro-variation in their cuisine, since there is more likely to be an accepted (best) form for any dish or food. While Americans expect to choose whether to have French fries, mashed potatoes, baked potatoes, or home-fried potatoes with their steak, the French assume that steak goes with frites (French fried potatoes). We have already reported that in comparison to Americans, French prefer fewer ice cream choices and expect fewer choices at each course in good restaurants (Rozin et al., 2006).

There are many ways to operationalize communal values; in this investigation, we do so in terms of desire for variety in different domains. As far as food and commensality are concerned, a lower preference for variety expresses a stronger concern about sharing in the communal experience, not "sticking out," hence a stronger sense of communal values. In the present study, by explicitly asking about desired variety in food and a number of other domains, we propose to both confirm the prior results for food, and see if they extend to other domains, as varied as shoes and automobiles.

\section{QUALITY VERSUS QUANTITY, AND THE RELATED MODERATION VERSUS ABUNDANCE}

The abundance-moderation dimension maps, at least at one end, on to the quantity-quality dimension. Clearly, abundance is associated with quantity, although moderation need not be associated with quality. Absence of excess, related to both abundance and quantity, is a long-standing theme in French eating. French food is generally considered to be elegant, sophisticated, and graceful (Levenstein, 2003b). Mennell (1996) draws the conclusion that the elegance and sophistication that we attribute to French food today originated from French gastronomic theory and the courtly model. Theorists wrote that gastronomy was about discrimination and moderation, with quality being more important than quantity. While daily French food is far from elegant, the influence of gastronomes in France impacted the manner in which the French regularly eat and inspired the value of moderation. Stearns (2002) makes a related point, actually linking moderation with esthetic desires, and hence quality. $\mathrm{He}$ notes that the French placed a strong emphasis on slenderness, fashion, and esthetics beginning in 1800, and still expected to enjoy high quality food. Therefore, great food without abundance became a necessity for them.

While the French dedicated themselves to discrimination and moderation, Americans were committed to abundance, or quantity (Stearns, 2002; Levenstein, 2003a,b). Levenstein (2003a) asserts that abundance is the American symbol of success and that food is the measure of America's abundance. Levenstein (2003a) points to a few examples of America's abundance, including the American supermarket and the enormous food supplies received by American soldiers in World War II. The meat ration for American soldiers was 10 ounces of beef, 4 ounces of pork, and 2 ounces each of chicken and bacon per person per day. "Never in the history of warfare, it was often said, had an army been as abundantly supplied with food as this one" (Levenstein, 2003a, p. 89). American abundance did not stop with the soldiers, for as Levenstein (2003b, p. 7) states, "Virtually every foreign visitor who wrote about American eating habits expressed amazement, shock, and even disgust at the quantity of food consumed."

There is direct evidence for the abundance-moderation or quantity-quality contrast in the American and French eating environments. French portion sizes are notably smaller than American portion sizes (Rozin et al., 2003), at the same time as French food is more expensive than American food. According to one estimate, the French spend a much larger proportion of their household income on food than Americans do (13.8 versus 5.7\%; http://www. ers.usda.gov/briefing/cpifoodandexpenditures/data/2006table97. htm). In the present study, we operationalize the quality-quantity distinction as a dimension, and ask individuals for their optimal point on this dimension for eight domains of life, including food, clothing, houses, and friends. 


\section{COMFORTS VERSUS JOYS}

Scitovsky (1992), in The Joyless Economy, draws a distinction between comforts and pleasures. (We prefer the word "joy" to Scitovsky's "pleasure." Essential to Scitovsky's distinction is the idea that comforts are rather long in duration of action, whereas pleasures are much shorter in time, often almost momentary. We believe the word "joy" implies this short or phasic property better than the word "pleasure," and make that substitution here and further on in this paper.) In Scitovsky's view, comfort seeking behaviors secure negative goods, such as freedom from pain, unpleasantness, or discomfort. Comforts, such as high quality mattresses, good air-conditioning, and automated controls in the home and the car, make life easier. They keep arousal at a moderate level. They provide a background for life. Joys on the other hand, are positive events, often unique occurrences, and are associated with increased arousal. Joys are usually occasions, like going to concerts, having a good meal, spending time with friends, and travel. They are in the foreground of life. They are more likely to involve social interactions. Scitovsky (1992) points out that joys and comforts compete, in that they push arousal in different directions, and since both cost money, they compete for expenditures. Scitovsky suggests that Americans prefer comforts much more than do Europeans. In a sense, he is claiming that American life is more comfortable, and European life is more interesting. Research on well-being, particularly on hedonic adaptation (e.g., Frederick and Loewenstein, 1999) and different temporal perspectives on pleasure (e.g., Kahneman et al., 1997) adds another perspective to the understanding of comforts and joys. Comforts are steady changes, and are just the kind of things we adapt to. We notice our air-conditioning only when it breaks. We rarely discuss how good last year was by referring to the quality of our air-conditioning system. Joys almost always involve a rather sudden change in affect and activity, and are much less likely to adapt. Furthermore, although both comforts and joys may contribute to experienced pleasure (probably less so for comforts), comforts add almost nothing to remembered pleasure, whereas joys are the very "stuff" of remembered pleasures. Most relevant is the distinction between experienced ("online") and remembered pleasure. For example, a comfortable beach vacation generates many fewer positive memories than a varied travel experience, just as a very positive but often repeated experience, as pleasant as it may be in experienced pleasure, does not create new memories (e.g., eating the same delicious dish at the same restaurant many times probably creates just "one" memory), unlike a new experience.

It is our sense, in agreement with Scitovsky, that the French, more than Americans, value joys as opposed to comforts. We observe this in the higher number of gadgets in kitchens and other parts of the home in America, the much higher incidence of air-conditioning in America, and the fact that the ratio of hotel room to meal prices is much higher in America. (The latter statement assumes that usually, a meal is more likely to be a joy than a hotel room.) We instantiate this in the questionnaire for this study, with questions about the relative importance of comfort or stability versus joys or excitement, in general and in specific domains of life.

\section{METHOD \\ PARTICIPANTS}

Brief one-page (two-sided) questionnaires were distributed to individuals waiting alone in major train stations in Philadelphia and Paris. This is a moderately representative sample, but it is biased in that individuals who were socializing, talking on their cell phones, or immersed in their work or a book were not approached. Additionally, some individuals refused to participate. Information about the number of participants in each country for each of the three questionnaires used is presented in Table 1. Data were collected from Americans in 2004 and 2006 and from the French in 2006. Including all the participants (from the three forms of the questionnaire), there is a modestly higher age in the French [mean age difference $=3.11$ years; $t(598)=2.346, p=0.019$ ] and substantially lower religiosity in the French [scale: $1=$ not religious at all to $5=$ extremely religious; mean difference $=0.49 ; t(582)=4.872, p=0.000]$.

\section{QUESTIONNAIRES}

Three different questionnaires were distributed. The questionnaires were originally composed in English, and were later translated into French and back-translated. We did two things in addition to backtranslation. First, two focus groups were run in each country prior to the designing of the questionnaire. One of their functions was to

Table 1 | Characteristics of participants.

\begin{tabular}{|c|c|c|c|c|c|c|c|c|}
\hline \multirow[t]{2}{*}{ Measure } & \multicolumn{2}{|c|}{ Version 1} & \multicolumn{2}{|c|}{ Version 2} & \multicolumn{2}{|c|}{ Version 3} & \multicolumn{2}{|c|}{ Total } \\
\hline & USA & France & USA & France & USA & France & USA & France \\
\hline$N$ & 126 & 91 & 98 & 99 & 83 & 104 & 307 & 294 \\
\hline Females $n(\%)$ & 60 (47.6) & $41(45.1)$ & $41(41.8)$ & $47(47.5)$ & $45(54.2)$ & $43(41.3)$ & $146(47.6)$ & $131(44.6)$ \\
\hline Age M (SD), Range & 37.6 (17.26), 73 & 38.6 (15.36), 72 & 36.7 (15.84), 61 & 41.1 (15.08), 63 & 40.4 (16.90), 58 & $43.6(16.41), 60$ & 38.2 (16.74), 76 & 41.1 (15.73), 72 \\
\hline Education > h.s. (\%) & 76 & 72 & 76 & 63 & 77 & 49 & 76.3 & 61.3 \\
\hline Religion \% & $37.5(29.2)$ & $5.6(43.3)$ & $33.3(25.8)$ & $8.3(49.0)$ & $26.8(41.1)$ & $5.7(45.7)$ & $32.5(32.0)$ & $6.5(46.0)$ \\
\hline \multicolumn{9}{|l|}{ Protestant (\% Catholic) } \\
\hline Religiosity ${ }^{1}$ & 2.95 & 2.26 & 2.78 & 2.48 & 2.94 & 2.47 & 2.89 & 2.40 \\
\hline
\end{tabular}

${ }^{1}$ Religiosity scale is 1, not at all religious to 5, extremely religious. 
identify the actual terms and phrases used by the participants - the "native" language and categories, as it were. The second precaution consisted of systematic testing of various phrasings of the translated questions. We made several phone calls to native speakers and tried various forms, identifying possible misunderstandings or biases. One additional factor was multilingualism: one of the principal investigators was very fluent in the languages surveyed and so were several research associates.

The questionnaires were anonymous and approved by the Internal Review Board to protect human subjects at the University of Pennsylvania. In order to make the questionnaire brief and userfriendly we divided it into three different versions. The briefness was dictated by the fact that the questionnaires were distributed to people waiting in train stations. Each questionnaire occupied two sides of one-page. All versions included the same demographic items as well as items concerning frequency of dieting, and the importance of variety in different domains. The specific items relevant to the issues raised in this paper are discussed along with the presentation of the results on these items.

The two items that were included on all three versions of the questionnaire are described below. The item asking about frequency of dieting was: "How often do you diet for purposes of weight loss? a. never, b. sometimes, c. usually, and d. always." Responses were coded on a scale of $0-3$.

The set of items that measured desire for variety directly, included eight-items each directed at a particular domain. The same question was asked for each domain, as follows:

For some items you may like to have a lot of choices to pick from and for other items the number of choices may not be as important to you. Assign a number, from the options below, to each item based on how much choice you like to have. $1=$ no choice, $2=$ few choices (1-5), $3=$ a moderate number of choices (5-15), and $4=$ many choices (over 15).

The eight domains were, in the order asked: Cars, Cell phone plans, Fruits in a grocery store, Menu choices, Ice creams, Shoes, Blouses/shirts, and Health insurance plans.

In version one, participants were asked to write about their day yesterday and their dinner last night. We do not report these results here, but we do include the results from these participants on the common items on frequency of dieting and on variety.

Version two included some free associations not presented in this paper, and a set of items contrasting desire for quantity versus quality in a number of domains. The items read as follows:

There are some domains in your life where quality is more important, and others where quantity (how many you have) is more important, for you. Rate each of the domains or situations below as to the relative importance of quality and quantity for you. 1 meaning quality is of the highest importance and 5 meaning quantity is of the highest importance.

The domains included Money (quality refers to things like newness of bills, quantity refers to amount), Stoves (quality meaning one excellent stove, quantity referring to more than one stove), Meals, Shoes, Tickets (quality meaning excellent seats for a few shows/ events, or quantity referring to poor seats for many shows/events), Friends (quality meaning a few very close friends, or quantity referring to many not as close friends), Houses (one great house versus two average houses, such as a summer home and a winter home),
Food (your favorite food in a smaller quantity or more dishes of not quite as good food), Clothes, and Vacation (1 week at a luxury resort versus 2 weeks at a less expensive resort for the same price, in the same place). The money and stove options were included just to help calibrate responses. They are not included in the data analysis, and were inadvertently not included in the French translation.

Version three consisted of all multiple-choice items and included principally items having to do with comforts and joys. There is a subset of three of these questions written in parallel forms that address a specific subset of joy-comfort concerns. The items in this section include: (1) When I go to my favorite restaurant, I choose to order... A. my favorite item on the menu or B. a new item that I have never tried, (2) When I go to hear my favorite musical artist perform, I prefer to hear... A. my favorite piece/song or B. a new piece/song, and (3) When I travel, I usually choose to go to... A. my favorite vacation spot or B. a new vacation spot that is supposed to be excellent. These three items pit an almost certain positive experience and positive anticipation, with minimal creation of new memories, against a less certain positive experience and anticipation, but a greater likelihood of creating a distinct new positive memory. Alternatively, this can be seen to be about experiencing something familiar and positive (more like a comfort) or creating a new, hence perhaps more interesting and surely more memorable experience (more like a joy).Version 3 contained an additional 13 items that we believed were reasonable measures of the comfort-joy distinction. Therefore, altogether the questionnaire contained 16 items that were designed to tap into the comfort-joy distinction. We discarded three of the 16 candidate items, two because $95 \%$ or more of participants made the same choice for the item, and the other because of a problem in translation from English to French, that changed the meaning of the item (see Table 6 for a description of the remaining items). The remaining 13 items were all adjusted so that a maximum score of one indicated joy and a minimal score of zero indicated comfort.

\section{RESULTS}

We organize results in terms of the three major differences we explore: variety/communal values, quality versus quantity, and comforts versus joys. The exact questionnaire items used are presented in the text, tables, or table legends in the appropriate sections. Because of multiple comparisons, we use as a measure of significance a level of $p<0.01$, two-tailed. However, in the tables we mark 0.05, 0.01, and 0.001 boundaries. Combined variables are named for the theme they represent (abbreviated as VAR for collective values, Q for qualitative-quantitative, and CJ for comfort and joy) followed by a descriptive term of the subset of scores they represent (e.g., VARLG is variety preference for large items, VARALL refers to all variety items) followed by the number of items in the score, followed by AVG standing for average. Before considering the results from the three major themes that are the focus of this paper, we present the results on a single item, dieting frequency, to confirm a previously established difference (Rozin et al., 1999) and in that sense, to provide some validation of our samples.

\section{DIET FREOUENCY}

Dieting is substantially and significantly less frequent in the French and in males and there is no culture by gender interaction (Tables 2 and 3 ). 
Table 2 | Means (SD) on combined variables and DIETFREQ by groups.

\begin{tabular}{lllllr}
\hline Variable $^{1}$ & France & USA & Female & Male $^{3}$ & $\boldsymbol{r}_{\text {With religiosity }}$ \\
\hline DIETFREQ & $0.58(0.64)$ & $0.83(0.86)^{* * *}$ & $0.96(0.78)^{* * *}$ & $0.49(0.70)$ & $0.11^{* *}$ \\
VARSM5AVG & $2.90(0.42)$ & $3.20(0.54)^{* * *}$ & $3.12(0.44)$ & $2.99(0.52)^{* *}$ & 0.07 \\
VARLG3AVG & $2.30(0.54)$ & $2.73(0.67)^{* *}$ & $2.42(0.60)$ & $2.61(0.66)^{* * *}$ & $0.13^{* *}$ \\
VARALL8AVG & $2.68(0.36)$ & $3.03(0.50)^{* * *}$ & $2.85(0.41)$ & $2.85(0.49)$ & $0.11^{* *}$ \\
QSM6AVG & $1.67(0.55)$ & $2.10(0.74)^{* * *}$ & $1.78(0.68)$ & $2.97(0.67)^{*}$ & 0.09 \\
QLG2AVG & $2.63(1.31)$ & $2.47(0.98)$ & $2.74(1.29)$ & $2.08(0.63)$ & -0.02 \\
QALL8AVG & $1.91(0.62)$ & $2.20(0.68)^{* *}$ & $2.01(0.70)$ & $0.46(0.34)$ & -0.07 \\
CJFAV3AVG & $0.50(0.33)^{* *}$ & $0.38(0.27)$ & $0.43(0.27)$ & $0.58(0.34)$ & -0.11 \\
CJFACTOR1 & $0.53(0.33)$ & $0.68(0.31)$ & $0.62(0.31)$ & $0.50(0.30)$ & -0.04 \\
CJFACTOR2 & $0.58(0.26)^{* * *}$ & $0.41(0.27)$ & $0.49(0.26)$ & $0.57(0.34)$ & $-0.23^{* *}$ \\
CJFACTOR3 & $0.69(0.29)^{* * *}$ & $0.40(0.31)$ & $0.58(0.31)$ & $0.65(0.39)$ & -0.13 \\
CJFACTOR4 & $0.67(0.38)$ & $0.68(0.37)$ & $0.70(0.36)$ & $0.56(0.20)$ &
\end{tabular}




${ }^{* * *} p<0.001$ ). ${ }^{3}$ Significance of Male-Female difference. ${ }^{4} \mathrm{~N}=583$ for religiosity, $n=596$ for diet frequency, $n=568$ for variety variables, $n=188$ for quantity variables, and $n=187$ for CJ variables..

Table 3 | Sex $\times$ country ANOVA on combined variables.

\begin{tabular}{|c|c|c|c|c|c|}
\hline Variable & $F$ country ${ }^{1}$ & $F \operatorname{sex}^{2}$ & $\begin{array}{l}\text { F country } \\
x \text { sex }\end{array}$ & Mult $r$ & $N$ \\
\hline DIETFREQ & $17.109 * * * A$ & $62.677 * * * \mathrm{~F}$ & 2.671 & 0.35 & 596 \\
\hline VARSM5AVG & $53.642 * * * A$ & $10.305^{* * *} \mathrm{~F}$ & 0.120 & 0.32 & 568 \\
\hline VARLG3AVG & $75.502 * * * A$ & $15.881 * * * \mathrm{M}$ & 3.732 & 0.37 & 568 \\
\hline VARALL8AVG & $92.695 * * * A$ & 0.010 & 0.613 & 0.38 & 568 \\
\hline QSM6AVG & $20.571 * * * A$ & 2.603 & 1.463 & 0.35 & 188 \\
\hline QLG2AVG & 0.634 & 3.618 & 0.082 & 0.16 & 188 \\
\hline QALL8AVG & $9.450 * * A$ & 0.141 & 1.159 & 0.23 & 188 \\
\hline CJFAV3AVG & $9.756 * * \mathrm{~F}$ & 0.064 & 0.104 & 0.23 & 185 \\
\hline CJFACTOR 1 & $8.594 * * A$ & 0.183 & 0.031 & 0.22 & 187 \\
\hline CJFACTOR 2 & $22.535 * * * \mathrm{~F}$ & 0.062 & 0.097 & 0.33 & 187 \\
\hline CJFACTOR 3 & $40.472 * * * F$ & 1.117 & 0.294 & 0.43 & 187 \\
\hline CJFACTOR 4 & 0.100 & 0.563 & 1.587 & 0.11 & 187 \\
\hline CJALL13AVG & $9.119 * * \mathrm{~F}$ & 0.836 & 0.048 & 0.22 & 187 \\
\hline
\end{tabular}

${ }^{*} p<0.05,{ }^{* *} p<0.01,{ }^{* *} p<0.001 .{ }^{1}$ For significant differences, letter after indication of significance indicates the group that had a higher score (more variety, quantity, or joy) $F=$ France, $A=U S A .{ }^{2}$ For significant differences, letter after indication of significance indicates the group that had a higher score (more variety, quantity, or comfort) $F=$ Female, $M=$ male.

\section{DESIRE FOR VARIETY}

One set of items measured desire for variety directly, with eightitems each directed at a particular domain (see Table 4). For all eight-items, the Americans scored higher on variety preference. The differences were all significant at least $p<0.01$, except ice cream, with six of eight significant at $p<0.001$ (Table 4). A factor analysis (SYSTAT, principal component, oblimin rotation) indicated a two factor solution. The first unrotated factor accounted for $35 \%$ of the variance, and after an oblimin rotation, the first factor explained $26 \%$ of the variance and the second
Table 4 | French and American scores on all items bearing on variety [mean (SD)].

\begin{tabular}{lll}
\hline Item & Mean: France & Mean: USA \\
\hline 1. Blouses/shirts & $3.00(0.66)$ & $3.34(0.99)^{* * *}$ \\
2. Shoes & $3.07(0.65)$ & $3.25(0.80)^{* *}$ \\
3. Fruits in a grocery store & $3.04(0.57)$ & $3.29(0.74)^{* * *}$ \\
4. Ice creams & $2.68(0.77)$ & $2.83(0.95)^{*}$ \\
5. Menus & $2.75(0.66)$ & $3.33(0.71)^{* * *}$ \\
7. Cars & $2.44(0.85)$ & $2.91(0.91)^{* * *}$ \\
8. Cell phones & $2.20(0.65)$ & $2.55(0.84)^{* * *}$ \\
9. Health insurance plans & $2.29(0.65)$ & $2.75(0.87)^{* * *}$ \\
\hline${ }^{*} p<0.05,{ }^{*} p<0.01,{ }^{* *} p<0.001$. & $N=290 \mathrm{FRENCH}, N=298$ American.
\end{tabular}

explained $23 \%$ of the variance. The two factors could be easily interpreted as five small/perishable items (blouses/shirts, shoes, fruits, ice cream, and menu selection) and three more expensive/durable items (cars, cell phone plans, and health insurance plans). Separate scores corresponding to the two factor scores were created by averaging scores for the five small (VARSM5AVG) and the three large/durable (VARLG3AVG) items. The means for these scores and for a combined score for all eight variety items (VARALL8AVG) separately for French and Americans, and males and females, are presented in Table 2. Corresponding results from Analyses of Variance with Country and Gender as factors are presented in Table 3. The American scores are significantly higher $(p<0.001)$ for the averaged five small and averaged three large/durable items, as well as for a score made by averaging all eight-items (Tables 2 and 3). Although there is no gender effect for the full eight-item averaged variety measure, females show a greater preference for variety for the smaller items, and males show a greater preference for variety in the larger/durable items (Tables 2 and 3 ). 
Given that the small item variety and large item variety scores correlate 0.41 ( 0.28 for France, 0.40 for USA), and that the Cronbach alpha for the eight-item scale is 0.73 , the eight-item averaged score (VARALL8AVG) represents a general preference for variety, and at least one component of what might eventually be a measure of communal versus individual food values.

Liking for variety is weakly correlated with religiosity $(0.11$, $p<0.01)$. This weak relation seems to primarily result from the fact that Americans are more religious and prefer variety more. Religiosity correlates with VARALL8AVG only 0.01 for Americans and 0.04 for French.

\section{QUALITY VERSUS OUANTITY}

In parallel to the measures on variety, the basic measure of the relative importance of quality versus quantity is a set of questions that directly address this contrast across eight domains (see Table 5).

In seven of eight cases, the French score lower on quantity (hence higher on quality) than the Americans (Table 5). The one exception had to do with houses, where the French preferred (non-significantly) quantity more than Americans. Four of the remaining seven differences reveal a significantly higher quantity preference for Americans (at $p<0.01$ or better). A principal component factor analysis (SYSTAT) of these eight-items revealed a two factor solution. With an oblimin rotation, the first factor accounted for $34 \%$ of the variance and the second $21 \%$ of the variance. As with variety, the items sorted in terms of the type of entity; small/inexpensive (food, meals, clothes, shoes, and ticket) along with "friends," versus larger/more expensive (house, vacation). "Friends" stands out as conceptually not belonging in either category, but falls statistically with the small/inexpensive factor. We created two factor scores by averaging the six components of the small/ inexpensive factor (QSM6AVG) and the two components of the large/ expensive factor (QLG2AVG). Since these two scores correlated 0.28 (0.29 USA, 0.42 France), and a Cronbach alpha on a scale that included all eight-items was 0.74 , we also included the average of all eight-items (QALL8AVG). Americans were significantly more quantity oriented for the first (small item) factor ( $p<0.001$, Tables 2 and 3 ), while the French were insignificantly more quantity oriented for the second (large item) factor (Table 2). The eight-item combined quantity score was significantly higher in the Americans ( $p<0.01$, Table 2$)$. None of the three combined quantity scores showed any significant effects of gender or gender by country interactions (Table 3 ).

Table 5 | French and American scores on quality versus quantity [mean (SD)].

\begin{tabular}{lll}
\hline Item & France & USA \\
\hline 1. Meals & $1.67(0.78)$ & $2.01(1.00)^{* *}$ \\
2. Shoes & $1.83(0.91)$ & $2.13(1.00)^{*}$ \\
3. Tickets & $1.79(1.01)$ & $2.34(1.17)^{* * *}$ \\
4. Friends & $1.41(0.67)$ & $1.72(1.10)^{*}$ \\
5. Food & $1.47(0.61)$ & $1.99(1.17)^{* * *}$ \\
6. Clothes & $1.88(1.00)$ & $2.42(1.10)^{* * *}$ \\
7. Houses & $2.50(1.54)$ & $1.96(1.18)^{* *}$ \\
8. Vacation & $2.75(1.49)$ & $2.98(1.32)$
\end{tabular}

${ }^{*} p<0.05,{ }^{*} p<0.01,{ }^{* * *} p<0.001 . N=98$ for France, $N=90$ for USA.
Since the French score higher on one item (house), it is unlikely that the French-American difference on quantity is simply a result of different biases in use of the scale. None of the three combined scores correlated significantly with religiosity. The overall eightitem quantity score correlated 0.24 ( $p<0.01 ; 0.29$ France, 0.30 USA) with the overall eight-item variety score, suggesting a link between a desire for quantity over quality and a desire for more variety.

\section{COMFORTS VERSUS JOYS}

The third version of the questionnaire contained the questions that focused on the comfort-joy distinction. There is a subset of three of these questions written in parallel forms that address a specific subset of joy-comfort concerns (see Methods). We predict, in accord with the hypothesis that the French are less comfort and more joy oriented, that they will opt more frequently for the new positive, but less certain experience. Our prediction holds, to different degrees for the three items (Table 6), with only one, for music, significant. The three favorite items inter-correlate positively (mean inter-item $r=0.22$, all positive and between 0.20 and 0.25 ), yielding a Cronbach alpha of 0.46 . The three scores are averaged into a new score, CJFAV3AVG, which is significantly higher in the French (Table 2). There are no significant effects of gender or gender by country interaction (Table 3 ).

We also analyzed the 10 additional items that measured the comfort-joy distinction. Of all 13 items, 10 yielded a higher joy score for French than Americans (Table 6). We are puzzled by the three that did not (Americans preferred more than the French a tropical hotel with a view as opposed to air-conditioning, a fulfilled as opposed to contented life, and a hotel plus theater tickets as opposed to a more luxurious hotel.) Of the 78 pairings of the 13 items, 18 were negatively correlated, the lowest at -0.17 .

The 13 items (see Methods; Table 6) were subjected to a factor analysis. A principal component analysis (SYSTAT) with oblimin rotation yielded a four factor solution that accounted for $52 \%$ of the total variance, with the highest factor intercorrelation at $r=0.13$. The factors were not particularly easy to differentiate conceptually, but they showed strikingly different relations to country. Factor 1, which we will call Stimulation 1, included four items that focused on adding stimulation (to a hotel stay or in more abstract terms, see Table 6). It was the only factor that showed a significantly higher joy score for the Americans ( $p<0.01$, Tables 2 and 3). Two of the three items that scored higher on joy for Americans are in this factor, as are two others which showed almost identical scores. Factor 2 , which we call Stimulation 2, has four items that are very similar, conceptually, to factor 1, again involving choices with more or less stimulation. All are about specific domains, two about food, one about music, and one about travel (vacations). This factor shows a very large $(p<0.001)$ difference, favoring more joy in the French (Tables 2 and 6). Factor 3 includes three items, none domain specific, and all of which explicitly address the idea of comfort as one of the alternatives. For this reason, we call it the comfort-joy factor. One item has to do with choice of metaphors for the ideal life (details in footnote 3 of Table 6), and two are dichotomous items. One presents a choice of the ideal life as comfortable or interesting, and a second with a choice of happiness as either comfort or excitement. This factor shows the largest French-American difference, strongly favoring joy for the French (Tables 2 and 6). The 
Table 6 | French and American scores on 13 items bearing on comforts versus joys'.

\begin{tabular}{lll}
\hline Item & No. neg rs & \multicolumn{1}{l}{ Mean: France } \\
& with 12 others &
\end{tabular}

\section{FACTOR 1}

Favorite versus new vacation site (see text)

What is more important to you in a tropical hotel room? A. air-conditioning; B. a view

What do you most desire your life to be like? stimulating versus stable (reverse scored)

What do you most desire your life to be like? contented versus fulfilled

FACTOR 2

Favorite versus new food (see text)

Favorite versus new music (see text)

Circle the word that you associate most closely with MEAL: nutrition/energy family/friends

If you were to vacation for a week, for the same price, would you rather:

$\begin{array}{lll}4 & 0.76 & 0.75 \\ 3 & 0.51 & 0.67^{*} \\ 2 & 0.53 & 0.52 \\ 5 & 0.30 & 0.74^{* *} \\ & & \\ ? ? & 0.41 & 0.31 \\ 0 & 0.33 & 0.06^{* * *} \\ 4 & 0.70 & 0.56 \\ & 0.87 & 0.69^{* *}\end{array}$

A. lie on a beautiful beach for a week; B. travel, sightsee, and engage in various activities

\section{FACTOR 3}

Ideal metaphors for life ${ }^{3}$

What do you most desire your life to be like? comfortable versus interesting

Circle the word that you associate most closely with HAPPINESS: comfort excitement

\section{FACTOR 4}

For the same price would you choose to: A. spend the night at a luxurious hotel;

B. spend the night at an average hotel and buy tickets to an excellent event

(such as a concert or sports event)

Imagine a vacation at an isolated resort with food included, for the same price

would you rather vacation for a week at: A. an average hotel with the best food;

B. a luxurious hotel with average food (reverse scored)



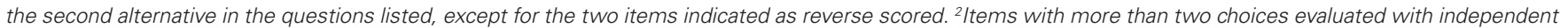

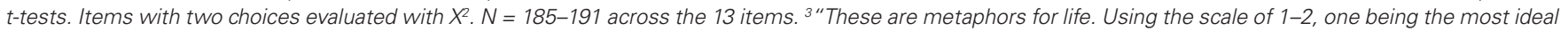

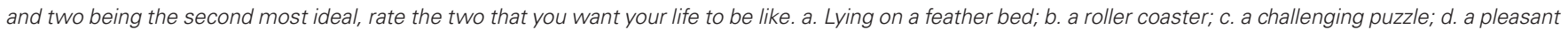





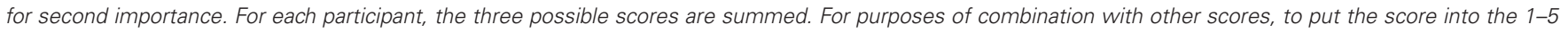
range of the other scaled scores, we added three to the summed score.

fourth factor, which includes two items about hotel preferences, contrasting luxury, or stimulation, shows no difference between French and Americans (Tables 2, 3, and 6).

An item that represents the average of all 13 items, CJALL13AVG (Cronbach alpha $=0.55)$, shows a significantly $(p<0.01)$ higher joy score for the French (Tables 2 and 3 ), but the country difference is smaller than the large differences on Factors 2 and 3, notably because the factor 1 items favor joy for the Americans.

\section{DISCUSSION}

On the basis of our knowledge of French and American culture and life, some historical writing about the two cultures, and our previous research, we proposed three potential general themes representing differences between French and American culture: Communal versus personal values, focus on quality as opposed to quantity, and greater emphasis on joys than comforts. We also linked a fourth theme, moderation versus abundance, in part, to the quality-quantity theme. We had gathered some evidence for higher French valuation of moderation, quality, and collective values in some of our prior work on food attitudes (Rozin et al., 1999, 2003, 2006). The purpose of this paper was to confirm these relationships within the food domain, extend the idea of joys versus comforts to the food domain, and then examine whether the three themes under investigation also appeared in other domains of life. We report evidence for a higher incidence of all three predicted differences (from the French perspective, communal values, quality, and joys) in food and in a number of other life domains. The results are highly significant, while at the same time, it is clear that there is a great deal of overlap between the French and Americans in valuation of these themes, and there are a few interesting "inversions" in particular domains.

The three themes that we have identified are not precisely defined, but rather are suggestions about clusters of beliefs or values. Through further conceptual analysis and measurements, it is hoped that more precise and empirically predictive formulations of the themes will occur.

The theme of communal versus personal values was instantiated in this study by desire for variety across domains. This is, of course, only one manifestation of this idea. What originally stimulated our thought about this theme was our own observations of the higher degree of ritualization of eating in France. We were impressed with, and documented (Rozin et al., 2006) the greater preference for a smaller number of choices in menus of French restaurants in France, and more particularly, that the main dish (usually meat 
with vegetables) seems much more often to be specified in detail in French restaurants (e.g., steak, French fries, and string beans) than in American restaurants (e.g., steak, your choice of potato, and your choice of vegetable). We interpret this as an example of the greater role of rules of appropriateness for food combinations (and particular sequences) in France, as well as greater respect for the chef as an arbiter of what is best to eat. As Lerner (1956) points out: "Frenchmen tend to be rigid in all matters associated with feeding... There is little deviation as to which wine goes with which food, and few venture from established rules" (p. 188; see also Fischler and Masson, 2008). Of our three themes, we expect that this one might be the most domain limited. We do not have the impression that French life is in general more "rule governed" than American life.

Quality versus quantity, as we have said, is related to the moderation versus abundance theme that our prior work on food portion size suggested (Rozin et al., 2003). Our results support generality of this theme. The one exception, houses, may be explainable in terms of another French theme, the focus on joys. The second house is typically a vacation house, and hence can be seen as a way to expand the diversity of life.

Joys versus comforts is, conceptually, the least well developed of our themes, and the items that we used to measure it are new, and need further work. Nonetheless, our findings support Scitovsky's (1992) proposal that comforts are relatively more important to Americans than to Europeans. There were three of thirteen items in which the predicted American preference for comfort did not appear. Two involved hotel choices, with the Americans preferring more than the French, a view to air-conditioning and a hotel plus theater tickets as opposed to a more luxurious hotel. The American preference for a hotel plus tickets as opposed to a more luxurious hotel may have tapped into the American inclination for quantity compared to the French value of quality. A luxurious hotel represents high quality, whereas a hotel room plus tickets implies getting a "bigger bang for the buck." Americans may have liked this idea of receiving more for the same amount of money. A third hotel item, involving a trade-off between better food and more luxurious room, showed almost the same score for French and Americans. This finding conflicts with our previous finding of greater importance of food (versus luxuriousness of hotels) in our previous research (Rozin et al., 1999). The preference for a new versus familiar vacation site was also about the same for French and Americans. We cannot explain why the hotel/vacation context revealed a different set of preferences from other domains.

The item showing the strongest American-French difference favoring Americans on the joy dimension is "What do you desire your life to be like? Contented or Fulfilled." Seventy-four percent of Americans endorsed "fulfilled" as opposed to only 34\% of French. And this in spite of the fact that more French than Americans endorsed "interesting" as opposed to "comfortable" for another item inquiring about the ideal life. We cannot easily account for this in terms of connotations of the words used in the translations, and remain puzzled about this finding. It may indicate some important clarification of the meaning of joys and comforts. It is possible that "fulfilled" does not signify more interesting, but rather, more directly, achieving one's own goals (which may be for money or comfort).
As we composed items on joys and comforts, we became aware of the difficulty of making this distinction, as well as confirming for ourselves the importance of the distinction. Are joys necessarily more interesting, more likely to produce memories, more actively engaging, more social? Can a night watching television while sitting on a comfortable sofa be meaningfully classified as a comfort or a joy? It is surely comfortable and somewhat passive, but it also involves a set of distinct experiences, assuming that the television program (be it sports, quiz show, news, or drama) contains a set of unique experiences and potential memories. It is our view that the best way to develop and articulate the joy-comfort distinction is through exercises such as we carried out in this study: thinking up examples, and trying them out on people. Our 16 comfort-joy items, with one exception (meal as nutrition or family/friends) tap the relatively narrow distinction between interesting/memorable versus more routine occurrences. We believe this is an important component of the comfort-joy distinction, and perhaps the easiest to instantiate with discrete questions. But the comfort-joy distinction engages much more than memorable, including arousal, anticipation, and sociality.

French-American differences we have reported are confounded with Catholic-Protestant differences. Although it is unlikely that this difference in religion explains all of the French-American differences under consideration, it is also likely that it has some explanatory potential. The Protestant tradition is characterized by a greater emphasis on self-discipline, on control of the body, and on individuality (Weber, 1977; Whorton, 1982; Stearns, 2002; Puhl and Brownell, 2003). Pleasure is more likely to be confounded with sin and guilt among Protestants (Weber, 1977). Stearns (2002) has invoked Protestantism as a partial explanation of French-American differences in the food and dieting domain. Both Whorton (1982) and Stearns (2002) argue that many Americans believe it is the individual's responsibility to remain healthy, fit, and slim, and if the individual fails then he or she can be deemed irresponsible. Puhl and Brownell (2003) note that American values of strict discipline, personal responsibility, and strong morality are rooted in the Protestant work ethic that pervades American culture. As a result, Americans place high value on self-control and blame the victim for not succeeding. Levenstein (2003a) suggests that Americans' "fat-phobia" is connected to the Protestant work ethic, because Americans attribute being fat to a lack of individual control. Following from this, Americans have attached a substantial moral component to health, dieting, and fat. Whorton (1982) writes of the moral component Americans attach to health in general.

While almost our entire French sample is Catholic, there are substantial numbers of Catholics and Protestants in the American sample. As a preliminary effort to explore Protestant-Catholic differences, we examined the scores of American Catholics versus Protestants on all of the summary variables listed in Table 2. There were no significant differences at $p<0.01$ (two-tailed) or better.

This study surely raises more issues than it settles, both for methodological and conceptual reasons. Acknowledging the methodological problems associated with comparing views expressed in different languages, we suggest preliminary, exploratory qualitative work (e.g., focus groups) can help identify "native" idiomatic language and categories, thus eschewing some of the problems 
classically arising from translation, in particular wording that sounds foreign, unfamiliar, misleading, or even meaningless to some interviewees. Although we did use focus groups in some of our previous studies, we were not able to do so in this particular one.

The study began with some hypotheses based on knowledge of the two countries and some prior literature. We gathered samples of adults from both countries that supported these ideas and helped to clarify and refine them. But this is just a first and preliminary step: some ideas, some evidence for them, and some subsequent refinement of the ideas, as indicated in this discussion. We feel this is a contribution to cultural psychology in that it raises three types

\section{REFERENCES}

Bell, R., and Pliner, P. (2003). Time to eat: the relationship between the number of people eating and meal duration in three lunch settings. Appetite 41, 215-218.

de Castro, J. M., and Brewer, E. M. (1992). The amount eaten in a meal is a power function of the number of people present. Physiol. Behav. 51, 121-125.

Fischler, C., and Masson, E. (2008). Manger. Francais, Europeéns et Américains face à l'alimentation. Paris: Odile-Jacob.

Fiske, A. P., Kitayama, S., Markus, H. R., and Nisbett, R.E.(1998). “The cultural matrix of social psychology," in The Handbook of Social Psychology, Vol. 2, 4th Edn, eds D. T. Gilbert, S. T. Fiske, and G. Lindzey (New York: McGrawHill), 915-981.

Frederick, S., and Loewenstein, G. (1999). "Hedonic adaptation," in Well-Being: The Foundations of Hedonic Psychology, eds D. Kahneman, E. Diener, and N. Schwarz (New York: Russell Sage Foundation), 302-329.

Kahneman, D., Schkade, D., Fischler, C. Krueger, A. B., and Krilla, A. (2010). "The structure of well-being in two cities: life satisfaction and experienced happiness in Columbus, Ohio; and Rennes, France," in International Differences in Well-Being, eds E. Diener, J. Helliwell, and D. Kahneman (Oxford: Oxford University Press), 16-33.

Kahneman, D., Wakker, P. P., and Sarin, R. (1997). Back to Bentham? Explorations of the experiences utility. Q. J. Econ. 12, 375-405.
Kitayama, S., and Cohen, D. (eds). (2007). Handbook of Cultural Psychology. New York: Guilford.

Krueger, A., Kahneman, D., Fischler, C., Schkade, D., Schwarz, N., and Stone, A. (2009). Time use and subjective wellbeing in France and the U.S. Soc. Indic. Res. 93, 7-18.

Laurier, D., Guiguet, M., Nguyen, P. C., Wells, J. A., and Valleron, A. J. (1992). Prevalence of obesity: a comparative survey in France, the United Kingdom and the United States. Int. J. Obes. 16, 565-572.

Lerner, D. (1956). Interviewing the Frenchmen. Am. J. Sociol. 62, 187-194.

Levenstein, H. (2003a). Paradox of Plenty: A Social History of Eating in Modern America, Revised Edition. Berkeley: University of California Press.

Levenstein, H. (2003b). Revolution at the Table: The Transformation of the American Diet. Berkeley: University of California Press.

Markus, H. R., and Kitayama, S. (1991). Culture and the self: implications for cognition, emotion, and motivation. Psychol. Rev. 98, 224-253.

Mennell, S. (1996). All Manners of Food: Eating and Taste in England and France from the Middle Ages to the Present, Revised Edition. Urbana: University of Illinois Press.

Nisbett, R. E. (2003). The Geography of Thought: How Asians and Westerners Think Differently and Why. New York: Free Press.

OECD. (2009). "Society at a glance", in OECD Social Indicators (Paris:

of cultural differences that have received little or no consideration before and provides some evidence for them. The evidence is not strong, and more conceptual work, better scales, and better and larger samples would be necessary to fully develop the three themes we present. More thinking and more data collection would be necessary to produce useful and coherent scales to represent each of our three themes. In particular, the comfort-joy distinction needs further exploration, at both the conceptual and empirical levels. This would include an extension of this contrast, to comparisons of other countries and cultures, and relating this distinction to economic/expenditure measures, and measures of quality of life.

Organization for Economic Co-operation and Development) 132.

Payer, L. (1988). Medicine and Culture. New York: Henry Holt and Company. Puhl, R. M., and Brownell, K. D. (2003). Psychosocial origins of obesity stigma: toward changing a powerful and pervasive bias. Obes. Rev. 4, 213.

Renaud, S., and de Lorgeril, M. (1992). Wine, alcohol, platelets, and the French paradox for coronary heart disease. Lancet 339, 1523-1526.

Rozin, P., Fischler, C., Imada, S., Sarubin, A., and Wrzesniewski, A. (1999). Attitudes to food and the role of food in life: comparisons of Flemish Belgium, France, Japan and the United States. Appetite 33, 163-180.

Rozin, P., Fischler, C., Shields, C., and Masson, E. (2006). Attitudes towards large numbers of choices in the food domain. A cross-cultural study of five countries in Europe and the USA. Appetite 46, 304-308.

Rozin, P., Kabnick, K., Pete, E., Fischler, C., and Shields, C. (2003). The ecology of eating: smaller portion sizes in France than in the United States help explain the French paradox. Psychol. Sci. 14, 450-454.

Scitovsky, T. (1992). The Joyless Economy: The Psychology of Human Satisfaction, Revised Edition. New York: Oxford University Press, 59-79.

Shweder, R. A. (1995). "Cultural psychology - what is it?" in Cultural Psychology. Essays on Comparative Human Development, eds J. W. Stigler, R. A. Shweder, and G. Herdt (Cambridge: Cambridge University Press), 1-42.
Sommer, R., and Steele, J. (1997). Social effects on duration in restaurants. Appetite 29, 25-30.

Stearns, P. N. (2002). Fat History: Bodies and Beauty in the Modern West. New York: New York University Press.

Weber, M. (1977). The Protestant Ethic and the Spirit of Capitalism. New York: Macmillan. (originally published 1904).

Whorton, J. C. (1982). Crusaders for Fitness: The History of American Health Reforms. Princeton, NJ: Princeton University Press.

Conflict of Interest Statement: The authors declare that the research was conducted in the absence of any commercial or financial relationships that could be construed as a potential conflict of interest.

Received: 08 October 2010; accepted: 14 July 2011; published online: 26 July 2011. Citation: Rozin P, RemickAK and Fischler C (2011) Broad themes of difference between French and Americans in attitudes to food and other life domains: personal versus communal values, quantity versus quality, and comforts versus joys. Front. Psychology 2:177. doi: 10.3389/fpsyg.2011.00177

This article was submitted to Frontiers in Cultural Psychology, a specialty of Frontiers in Psychology.

Copyright (C) 2011 Rozin, Remick and Fischler. This is an open-access article subject to a non-exclusive license between the authors and Frontiers Media SA, which permits use, distribution and reproduction in other forums, provided the original authors and source are credited and other Frontiers conditions are complied with. 